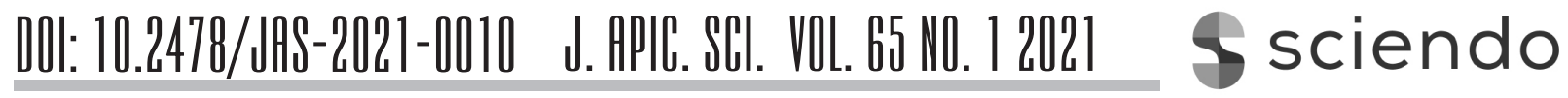

Original Article

\title{
APPLICATION OF HERBAL ESSENTIAL OIL EXTRACT MIXTURE FOR HONEY BEES (APIS MELLIFERA L.) AGAINST NOSEMA CERANAE AND NOSEMA APIS
}

\author{
Asli Özkıгım ${ }^{1,2}$ \\ Billur Küçüközmen ${ }^{1}$ \\ ${ }^{1}$ Hacettepe University, Department of Biology, Bee Health Laboratory, Beytepe- \\ Ankara, Turkey \\ ${ }^{2}$ Hacettepe University Bee and Bee Products Application and Research Center, \\ Beytepe-Ankara, Turkey \\ *corresponding author: asli.ozkirim@gmail.com \\ Received: 22 July 2020; accepted: 23 February 2021
}

A b s t r act

In recent years, interest in herbal essential oil extracts for the treatment of nosemosis has steadily increased. The great importance of this study is in evaluating and validating the synergistic effect caused by the mixture of different herbal extracts. The aim of the study was to investigate through cage experiments and field studies the effect of mixed herbal essential oil extracts and to determine the most suitable application methods and doses of the product in the treatment of nosemosis. The duration of the experiments was three weeks. Results show that the herbal essential oil extract mixture (HEOEM) is effective on both Nosema apis and Nosema ceranae, and on the two together (mixed infection). With respect to application methods, the results revealed that the most suitable method is spraying HEOEM with sterilized distilled water on adult bees and on both sides of frames; $500 \mu \mathrm{L}$ per cage and 2,000 $\mu \mathrm{L}$ per frame were found to be effective doses of HEOEM in the experimental cages and hives. HEOEM can be a viable alternative to synthetic products in the immediate future as the contents are natural and have no toxic effect on honey bees.

Keywords: application method, cage experiment, field study, herbal extract, honey bee, Nosemosis,

\section{INTRODUCTION}

Nosemosis is a widespread disease responsible for the loss of honey bee colonies in several countries (Neumann \& Carreck, 2010). The causative agents of nosemosis are the intracelIular fungi Nosema apis and Nosema ceranae belonging to the phylum Microsporidia, Nosematidae family. Nosema spp. infect the digestive system of honey bees (Higes et al., 2008). The distribution of $N$. apis and $N$. ceranae is now worldwide, as reported in various sources. Nosemosis can be treated with antifungal agents. While fumagillin has been used for decades to control nosemosis in managed honey bee colonies, a study has shown that this antibiotic poses a toxic threat and that its efficacy against $N$. ceranae is uncertain (Botias et al., 2013).

Interest in herbal alternatives for treatment has increased in recent years, because the contents are natural and do not leave a residue in bee products (Costa et al., 2010; Botias et al., 2013; Bravo et al., 2017). The antiseptic properties of some plants have motivated the search for herbal alternatives, and so herbal extracts and essential oils with many antimicrobial components are preferred. The synergistic effect that may occur between the components of such plant mixtures is also a desirable trait (Radoi et al., 2014; Andrade et al., 2018). However, each plant species in plant mixtures must not be toxic to bees.

The aim of this study was to investigate the efficacy of a herbal mixture against $N$. apis, $N$. ceranae, and mixed infections of both. The 
Table 1.

Plant properties and bioactivities considered in preparing HEOEM

\begin{tabular}{|c|c|c|c|}
\hline Species & Major components & Bioactivities & References \\
\hline $\begin{array}{l}\text { Rumex } \\
\text { acetosella }\end{array}$ & $\begin{array}{c}\text { Oxalate (binoxalate) of } \\
\text { potassium, tannic acid, and } \\
\text { nitrogenous matter }\end{array}$ & $\begin{array}{l}\text { Refrigerant, asidic } \\
\text { and diuretic }\end{array}$ & $\begin{array}{l}\text { https://www.henriettes- } \\
\text { herb.com/eclectic/kings/ } \\
\text { rumex-acet.html }\end{array}$ \\
\hline $\begin{array}{l}\text { Achillea } \\
\text { millefolium }\end{array}$ & $\begin{array}{l}\text { Artemisia ketone, camphor, } \\
\text { linalyl acetate and 1,8-cineole }\end{array}$ & $\begin{array}{c}\text { Anti-inflammatory } \\
\text { and } \\
\text { disinfectant }\end{array}$ & Ghanbari et al., 2017 \\
\hline $\begin{array}{l}\text { Plantago } \\
\text { lanceolata }\end{array}$ & $\begin{array}{l}\text { Flavonoids, alkaloids, terpenoids, } \\
\text { phenolic compounds (caffeic } \\
\text { acid derivatives), iridoid } \\
\text { glycosides, fatty acids, polysac- } \\
\text { charides and vitamins }\end{array}$ & $\begin{array}{l}\text { Anti-inflammatory } \\
\text { antimicrobial activity, } \\
\text { antioxidant and } \\
\text { cytotoxic activity, } \\
\text { anti-tumoural activity } \\
\text { and antispasmodic }\end{array}$ & Bajer et al., 2016 \\
\hline $\begin{array}{l}\text { Salvia } \\
\text { officinalis }\end{array}$ & $\begin{array}{l}\text { Cis-thujone, camphor, cineole, } \\
\text { humulene, trans-thujone, } \\
\text { camphene, pinene, limonene, } \\
\text { bornyl acetate and linalool }\end{array}$ & $\begin{array}{l}\text { Antibacterial, anti- } \\
\text { oxidant, antimicro- } \\
\text { bial, insecticidal and } \\
\text { allelopathic activities } \\
\text { antitumoral antidia- } \\
\text { betic and antioxidant }\end{array}$ & Khedher et al., 2017 \\
\hline $\begin{array}{l}\text { Thymus } \\
\text { vulgaris }\end{array}$ & $\begin{array}{c}\text { Geraniol, linalool, gamma-ter- } \\
\text { pineol, carvacrol, thymol and } \\
\text { trans-thujan-4-ol/terpinen-4-ol, } \\
\text { p-cymene, y-terpinene and } \\
\text { thymol }\end{array}$ & $\begin{array}{l}\text { Antimicrobial, antitus- } \\
\text { sive, antibroncholitic, } \\
\text { antispasmodic, } \\
\text { anthelmintic, car- } \\
\text { minative, antiseptic, } \\
\text { antioxidant, diuretic }\end{array}$ & Borugă et al., 2014 \\
\hline $\begin{array}{l}\text { Rosmarinus } \\
\text { officinalis }\end{array}$ & $\begin{array}{l}\text { Rosmarinic acid,caffeic acid, } \\
\text { ursolic acid, betulinic acid, } \\
\text { carnosic acid and carnosol, } \\
\text { camphor, 1,8-cineole, a-pinene, } \\
\text { borneol, camphene, } \beta \text {-pinene } \\
\text { and limonene }\end{array}$ & $\begin{array}{c}\text { Antibacterial, } \\
\text { antiviral, antioxidant } \\
\text { and anti-inflam- } \\
\text { mator, antidiabetic } \\
\text { anti-inflammatory, } \\
\text { antitumor and anti- } \\
\text { oxidant }\end{array}$ & Andrade et al., 2018 \\
\hline Laurus nobilis & $\begin{array}{l}\text { 1,8-cineole, sabinene, and } \\
\text { linalool }\end{array}$ & $\begin{array}{l}\text { Antibacterial, anti- } \\
\text { oxidant, antifungal, } \\
\text { cytotoxic }\end{array}$ & Caputo et al., 2017 \\
\hline
\end{tabular}

herbal essential oil extract mixture (HEOEM) contains Rumex acetosella, Achillea millefolium, Plantago lanceolata, Salvia officinalis, Thymus vulgaris, Rosmarinus officinalis and Laurus nobilis. These plants were selected because of their chemical constituents, major components and bioactivities reported in the literature, and the optimal mixture thought to be effective against Nosema spp. was created. The contents and bioactivity of these plants are summarized in Tab. 1.

Some herbal essential oils contained have been studied individually against Nosema spp., including Thymus vulgaris (Costa et al.,2010), Rosmarinus officinalis (Radoi et al., 2014), Laurus nobilis (Damiani et al., 2014) and Beta vulgaris (Botias et al.,2013), but nothing concerning the effects of herbal extract 
mixtures against nosemosis. The secondary objective in connection with this aim was to determine the most suitable application method, dosage and treatment duration of HEOEM against nosemosis.

\section{MATERIAL AND METHODS}

\section{Plant materials}

Rumexacetosella has a long, tapering, somewhat woody root with an erect, simple, leafy, striated stem $30-60 \mathrm{~cm}$ high. A cosmopolitan species, it inhabits every region of Turkey (Isbilir \& Sagiroglu, 2013). $R$. acetosella was collected in April and September 2018 in the Black Sea, the Mediterranean, and the central Anatolia regions of Turkey. Twenty-six mg/L of plant extract was used in HEOEM.

Achillea millefolium (Compositae or Asteraceae). Achillea species are the most important indigenous economic plants of Anatolia (Celik \& Akpulat, 2008). Herbal teas prepared from some Achillea species are traditionally used for abdominal pain and flatulence in Turkey (Honda et al., 1996). A. millefolium was collected in May and September 2018 in the Black Sea, southeast Anatolia and eastern Anatolia regions of Turkey. Eleven $\mathrm{mg} / \mathrm{L}$ of plant extract was used in HEOEM.

Plantago lanceolata is a herb species with a wide distribution in grasslands throughout the temperate world. P. lanceolata was collected in May and September 2018 in the Aegean, the Mediterranean, the Marmara and the Black Sea regions of Turkey. Thirty-one $\mathrm{mg} / \mathrm{L}$ of plant extract was used in HEOEM.

Salvia officinalis. Salvia, the largest genus of the Lamiaceae family, is native to the Mediterranean area and includes about 900 species (Walker et al., 2004). It is cultivated in all habitats of Turkey (Sorkun, 2008). S. officinalis was collected in May and July 2018 in the Aegean and the Mediterranean regions of Turkey. Seven $\mathrm{mg} / \mathrm{L}$ of plant extraction was used in HEOEM.

Thymus vulgaris. The Thymus genus includes one species cultivated as an aromatic plant ( $T$. vulgaris) and 18 other wild species. This plant can be cultivated in all regions of Turkey (Özcan
\& Chalcat, 2004). T. vulgaris was collected in May and October 2018 in the Aegean, the Mediterranean, southeast Anatolia, and the central Anatolia regions of Turkey. Twenty-three $\mathrm{mg} / \mathrm{L}$ of plant extract was used in HEOEM.

Rosmarinus officinalis is a dense bushy, branched, evergreen with a blue-white flower which reaches a height of about $1 \mathrm{~m}$ (Sorkun, 2008). R. officinalis was collected in March, April and May 2018 in the Aegean, the Mediterranean, southeast Anatolia and the central Anatolia regions of Turkey. Fourteen $\mathrm{mg} / \mathrm{L}$ of plant extract was used in HEOEM.

Laurus nobilis is an evergreen tree or shrub belonging to the family Lauraceae, native to the southern parts of Europe and the Mediterranean area. This plant is widely cultivated in many countries of the region (Sorkun, 2008). L. nobilis was collected in July and October 2018 in the Aegean and Mediterranean regions of Turkey. Nine $\mathrm{mg} / \mathrm{L}$ of plant extract was used in HEOEM.

\section{Essential oil distillation}

Hydrodistillation of the leaves of $R$. acetosella, A. millefolium, $P$. lanceolata, $S$. officinalis, $T$. vulgaris, $R$. officinalis, and $L$. nobilis harvested in different regions of Turkey yielded essential oils. One hundred grams of dried leaves were subjected to separate water distillation for six hours using a Clevenger-type apparatus (Özkırım et al., 2012). The yields of the essential oils were $2.6 \%, 2.4 \%, 1.8 \%, 2.1 \%, 0.9 \%, 1.2 \%$ and $1.1 \%$, respectively, on a dry weight basis.

\section{Nosema analyses}

Nosema analyses were done in two experiments, cage experiments and field study, using the spore counting method (Özkırım et. al., 2019) and PCR detection (Fries et al., 2013). The analyses were continued during the three weeks of the study period.

\section{Cage experiments}

Experimentalset-up. Thirty cages $\left(15 \times 15 \times 15 \mathrm{~cm}^{3}\right)$ contained 190 newly-emerged bees. The honey bees in all cages were fed syrup (1:1 w/v-homemade) and sterilized distilled water (SDW). After the first week, fourteen cages were infected 


\section{HEOEM for Nosema Treatment}
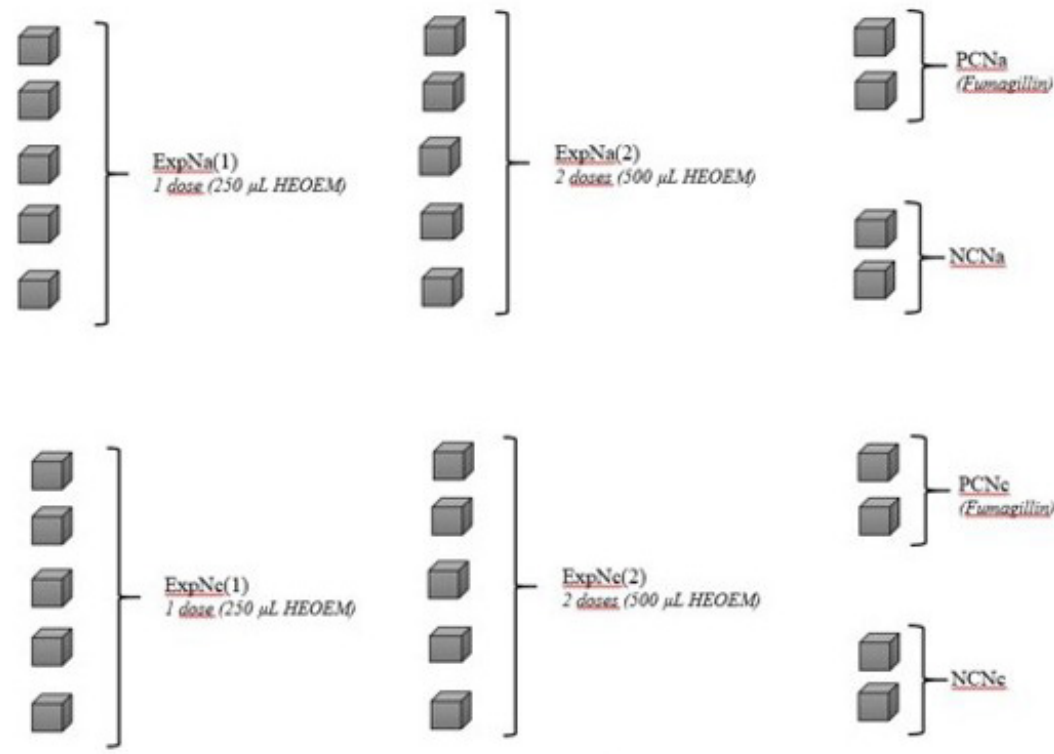

Fig. 1. Experimental design of the cage experiment.
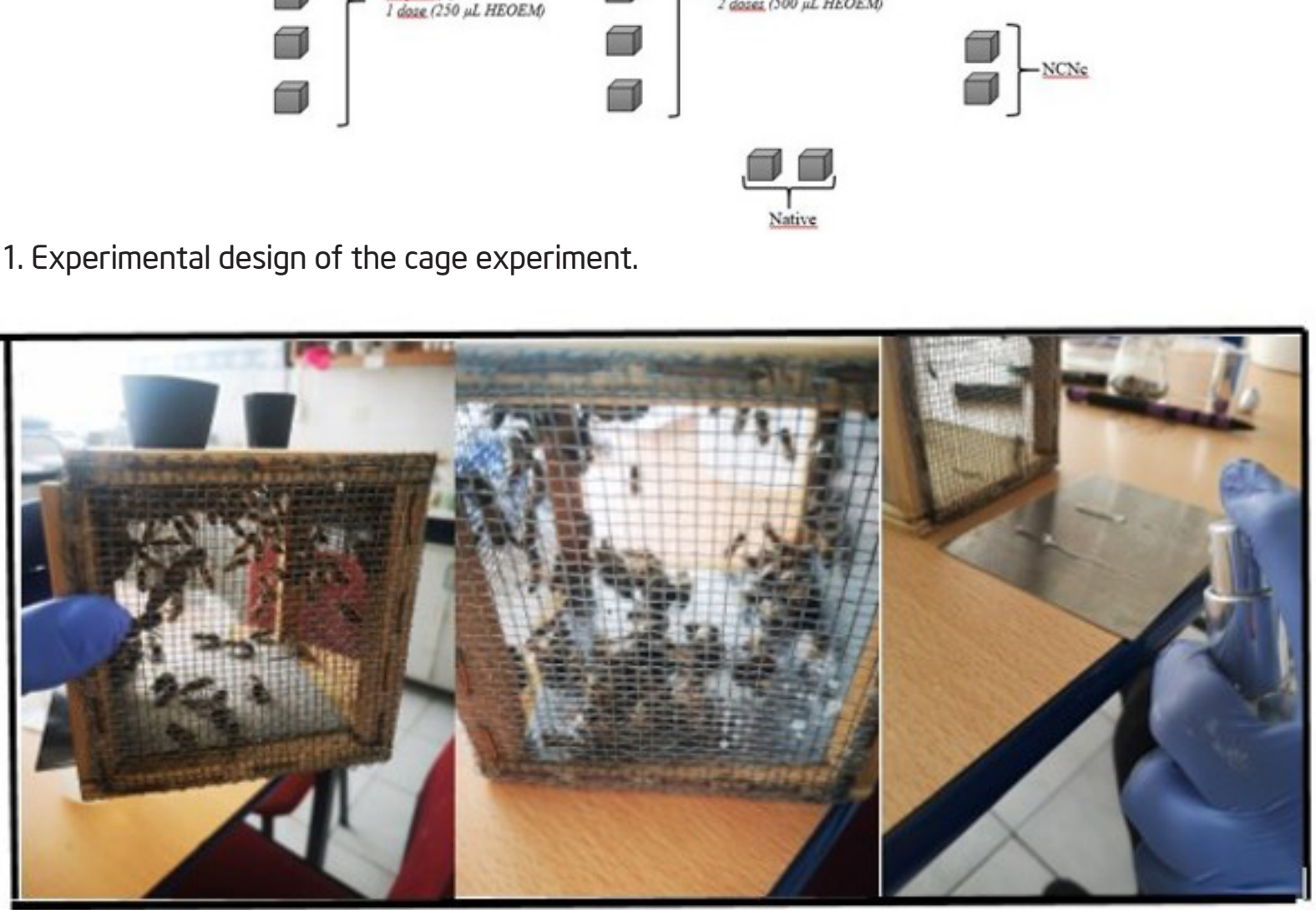

Fig. 2. HEOEM application method in the cage experiment by spraying the syrup on 190 adult bees in the $225 \mathrm{~cm}^{2}$ surface area of the experimental cages using a 30-ml glass spray bottle.

individually with $N$. apis spores isolated from the field and identified through PCR (Fries et al., 2013) by feeding $10 \mu$ of $N$. apis spore solution per bee $\left(1 \times 10^{8}\right.$ spore/ml). Three days after artificial infection, three bees from each cage were sampled and the number of Nosema spores was counted. The experiment began when tagging twenty cages were tagged as the experimental group, four cages as the positive control using fumagillin (two for $N$. apis and two for $N$. ceranae), and four cages as the negative control (two for $N$. apis and two for $N$. ceranae) having infected honey bees with no treatment applied. Two cages were tagged as native colonies which were not infected and only fed syrup. In all, the experiment consisted of ten experimental cages of $N$. apis, ten experimental cages of $N$. ceranae, two negative control cages of $N$. apis, two negative control cages of $N$. ceranae, two positive control cages of $N$. apis, two positive control cages of $N$. ceranae and two native control cages. The experimental 
design of the cage experiment is summarized in Fig. 1. Dead bees were collected from all cages every three days. The number of dead bees was recorded as the mortality data.

Application methods. Before all applications, three bees from each cage were sampled to count the number of $N$. apis and $N$. ceranae spores. This procedure was continued every three days throughout the experiment. The HEOEM, diluted 1/20 with 1:1 homemade sugar syrup (w/v), was sprayed from a 30 -ml glass spray bottle on 190 adult bees in the $225 \mathrm{~cm}^{2}$ surface area of the experimental cages with a sprayer (Fig. 2.). One spray dose contained 250 $\mu \mathrm{L}$ of the HEOEM solution. One $(250 \mu \mathrm{L})$ and two doses (500 $\mu \mathrm{L})$ of spray were applied to the two cross sides of the cages. Five experimental cages were examined for each dose. Fumagillin was applied through the feeding method with syrup; one hundred $\mu$ of fumagillin was added to $5 \mathrm{~mL}$ of syrup and applied to the positive control cages with the same frequency as the experimental groups. All applications were performed at three-day intervals six times during the experiment. The cage experiments lasted twenty-one days.

\section{Field study}

Experimental setup. Nine apiaries were chosen in different locations based on the beekeeping activities in the field studv in April 2019.

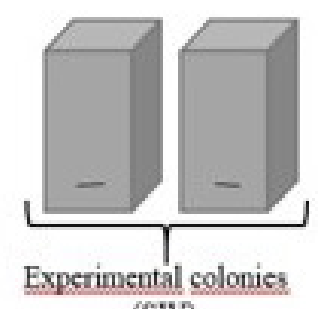

(SW)

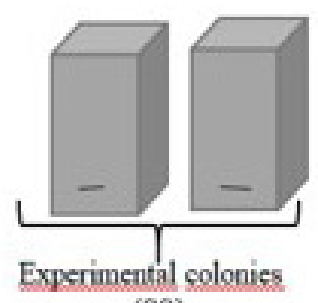

(SS)

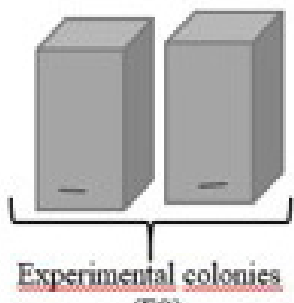

(FS)

Fig. 3. Experimental design of the field study.

The apiaries were assigned the same number as their location (e.g., Apiary 1 = Ankara). Each colony in the apiaries had six to eight frames full of adult bees. Eight colonies that had clinical signs of nosemosis were detected in each apiary and confirmed through PCR analyses (Fries et al., 2013). The infection type of the experimental colonies in the apiaries were $N$. apis in apiary 4, N. ceranae in apiaries 1, 2, 5 and 9, and mixed infection (both species) in 3, 6, 7 and 8. In addition, thirty bees from each colony were sampled and the number of Nosema spp. spores was counted. This procedure was continued every three days throughout the experiment. The experiment began with six experimental colonies comprised of eight colonies in each apiary. The six colonies were divided into three subgroups (two colonies each) for the different applications of HEOEM. The remaining two from the eight colonies were included in the experiment as positive and negative controls. Fumagillin was used to treat nosemosis through feeding with syrup in the positive control colonies. One hundred $\mathrm{mg}$ of fumagillin was added to five $L$ of homemade syrup $(1: 1 \mathrm{w} / \mathrm{v})$ and applied to the positive control colony in the same frequency as the experimental groups. No treatment was applied to the negative control colony. Experimental design diagrammed in Fig. 3.

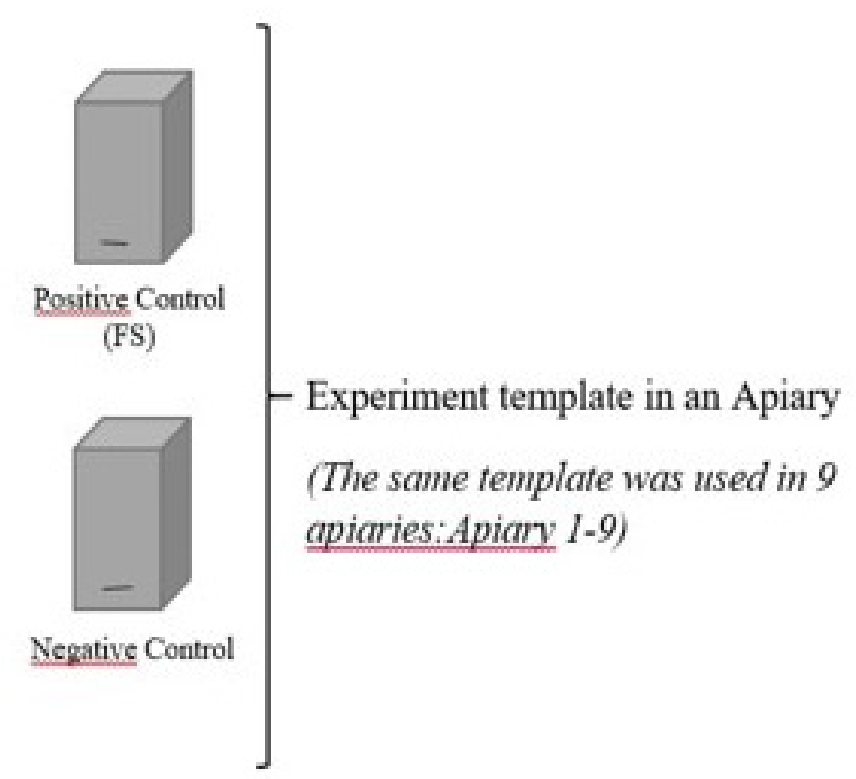


Application methods. In all experimental subgroups of the nine apiaries, HEOEM was tested with the application methods described below. The study lasted one month (April 2019), and each method was carried out over three weeks at three-day intervals.

a) spraying with water (SW): HEOEM was diluted 1/20 with SDW. HEOEM solution was sprayed over the $924 \mathrm{~cm}^{2}(220 \mathrm{~mm} \times 420$ $\mathrm{mm})$ surface area of the frames in the experimental colonies. This solution was applied to both sides of the comb surface and adult bees. One spray dose contained $250 \mu \mathrm{L}$ of HEOEM solution. Eight doses $(2,000 \mu \mathrm{L})$ of spray were applied to two sides of the frames, considering the surface area in the afternoon when all foragers came back to the hives. Applications were performed at three-day intervals six times during the experiment. This method was applied to two experimental colonies in each apiary.

b) spraying with syrup (SS): HEOEM was diluted 1/20 with 1:1 homemade sugar syrup (w/v) and sprayed on adult bees in the same doses as in method (a) and applied to two experimental colonies in each apiary.

c) feeding with syrup (FS): HEOEM was diluted 1/20 with 1:1 (w/v) homemade sugar syrup. This method was applied to two experimental colonies in each apiary.

Parameters for measuring HEOEM efficacy. The effectiveness of HEOEM was determined through the observation of the development of colonies, the presence of young individuals and the disappearance of clinical symptoms. A significant decrease in the number of Nosema spp. spores is a parameter that can be measured numerically. The combination of all parameters confirmed the treatment efficacy of HEOEM.

\section{Statistical analyses}

One-way ANOVA (SPSS version 22.0 software) and the Duncan test were performed to determine significant results in the efficacy of HEOEM and the application methods employed in the experimental groups.

\section{RESULTS}

The effectiveness of HEOEM application can be accurately assessed with the results of both the cage experiments and the field studies through statistical analysis in this research.

\section{Efficacy of HEOEM based on results of cage experiments}

During the cage experiments, the number of dead bees was recorded as mortality data (Tab. 2). These data demonstrate that HEOEM has no toxic effect on honey bees. Mass death was not encountered, and mortality was recorded at lower levels than in the control groups.

HEOEM was found to be significantly effective against Nosema spp. in all experimental groups

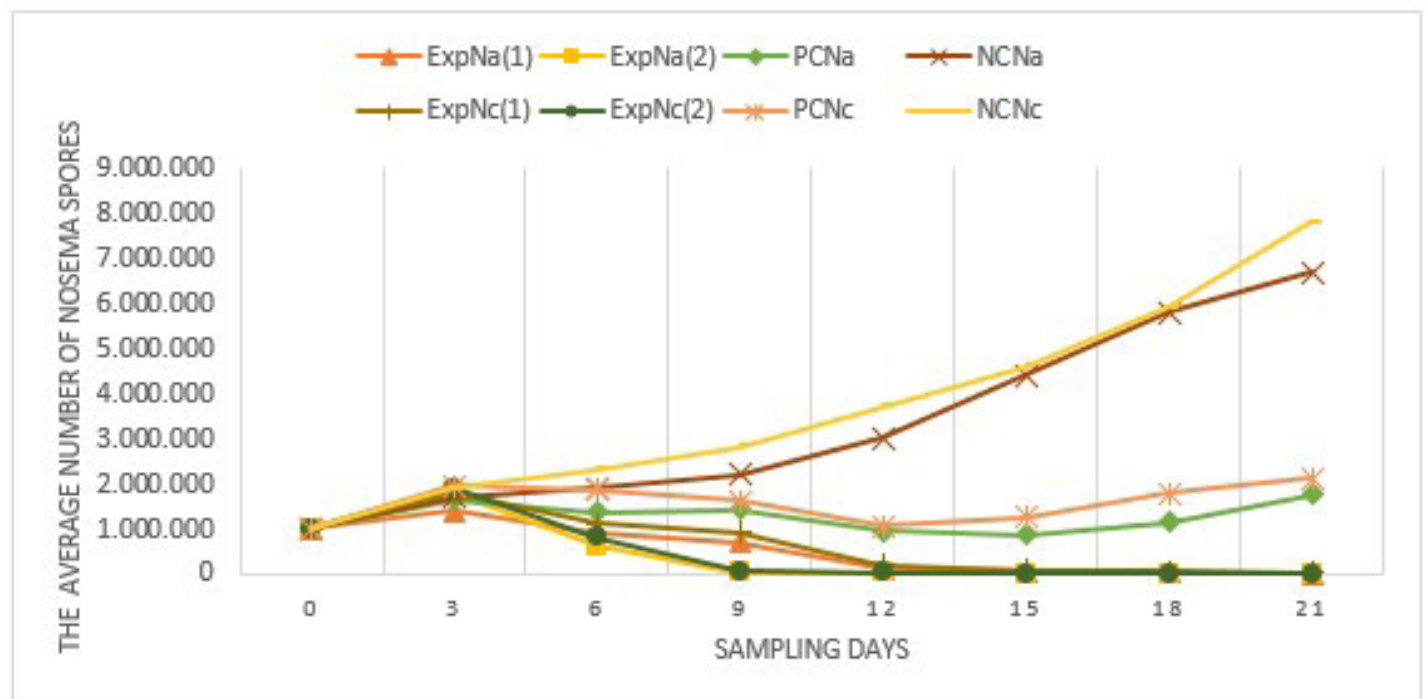

Fig. 4. The average numbers of Nosema spp. spores/bee during cage experiment in all groups. 
Table 2.

Number of dead bees and final mortality rates (\%) during the cage experiments

\begin{tabular}{cccccccccccc}
\hline & \multicolumn{1}{c}{ Sampling Days } & & $\begin{array}{c}\text { Total } \\
\text { number } \\
\text { of dead } \\
\text { bees }\end{array}$ & $\begin{array}{c}\text { Final mortality } \\
\text { rates(\%) }\end{array}$ \\
\hline Cages & $\begin{array}{c}\text { Cage } \\
\text { number }\end{array}$ & 3 & 6 & 9 & 12 & 15 & 18 & 21 & & & $\begin{array}{c}\text { (190 newly } \\
\text { emerged bees at } \\
\text { the beginning point } \\
\text { x10 cages) }\end{array}$ \\
\hline ExpNa(1) & $1-10$ & 5 & 15 & 33 & 48 & 63 & 85 & 93 & 342 & 18.0 \\
ExpNa(2) & $1-10$ & 5 & 15 & 17 & 29 & 34 & 51 & 64 & 215 & 11.3 \\
PCNa & $1-2$ & 0 & 6 & 15 & 11 & 20 & 27 & 53 & 132 & 34.7 \\
NCNa & $1-2$ & 1 & 11 & 20 & 31 & 59 & 95 & 117 & 334 & 87.8 \\
ExpNc(1) & $1-10$ & 8 & 14 & 32 & 39 & 85 & 108 & 165 & 451 & 23.7 \\
ExpNc(2) & $1-10$ & 8 & 11 & 29 & 33 & 51 & 81 & 102 & 315 & 16.5 \\
PCNc & $1-2$ & 0 & 13 & 15 & 22 & 30 & 48 & 70 & 198 & 52.1 \\
NCNc & $1-2$ & 15 & 25 & 46 & 59 & 70 & 105 & 59 & 380 & 100 \\
Native & $1-2$ & 1 & 5 & 8 & 10 & 12 & 10 & 15 & 61 & 16.0 \\
\hline
\end{tabular}

*ExpNa:Experimental $N$. apis cages; ExpNc: Experimental $N$. ceranae cages; PCNa: Positive Control $N$. apis cages; PCNc: Positive Control N. ceranae cages; NCNa: Negative Control N. apis cages; NCNc: Negative Control N. ceranae cages; Native: Non-infected cages

$\star *(1)$ and (2): Application doses of HEOEM

Table 3.

Differences between groups regarding application doses classified by Duncan test

\begin{tabular}{|c|c|c|c|c|c|c|}
\hline Subgroups & $\begin{array}{l}\text { Subset for } \\
\text { alpha } \\
=.05\end{array}$ & & The numb & er of Nosema sp & D. spores/bee $\pm S E$ & \\
\hline Cages & $\begin{array}{c}\mathrm{N} \\
\text { (Sampling } \\
\text { days) }\end{array}$ & $a^{\star}$ & $b^{*}$ & $c^{*}$ & $d^{*}$ & ${ }^{\star} \mathrm{e}$ \\
\hline $\operatorname{ExpNa}(2)$ & 8 & $428703 \pm 21.3$ & & & & \\
\hline $\operatorname{ExpNc}(2)$ & 8 & $471887 \pm 24.2$ & & & & \\
\hline ExpNa(1) & 8 & & $518812 \pm 28.1$ & & & \\
\hline ExpNc(1) & 8 & & & $639750 \pm 24.6$ & & \\
\hline PCNa & 8 & & & & $3337500 \pm 126.3$ & \\
\hline PCNc & 8 & & & & $3750000 \pm 131.7$ & \\
\hline $\mathrm{NCNa}$ & 8 & & & & & $41519226 \pm 336.3$ \\
\hline NCNC & 8 & & & & & $40621143 \pm 321.8$ \\
\hline
\end{tabular}

Means for groups in homogeneous subsets are displayed. *a,b,c,d are significantly different groups

in the cage experiments (Fig. 4). Significant ANOVA test $(F=14.587, d f=9, S i g=000, P<0.001$, differences $(P<0.05)$ in the number of Nosema $N=30)$. Statistical analyses revealed that a spp. spores were confirmed through one-way double-dose application (500 $\mu \mathrm{L}$ ) of HEOEM 


\section{- ÖZKR丨M Ee hl.}

Table 4.

Comparison of numbers of Nosema spp. spores following varying HEOEM application methods analysed by Duncan test

\begin{tabular}{cccccc}
\hline Subgroups & $\begin{array}{c}\text { Subset for } \\
\text { alpha } \\
=.05\end{array}$ & \multicolumn{2}{c}{ The number of Nosema spp. spores/bee $\left(\times 10^{6}\right) \pm S E$} \\
$\begin{array}{c}\text { Appl. } \\
\text { methods }\end{array}$ & $\begin{array}{c}\mathrm{N} \\
\text { (apiaries) }\end{array}$ & $\mathrm{a}^{\star}$ & $\mathrm{b}^{\star}$ & $\mathrm{c}^{\star}$ & $\mathrm{d}^{\star}$ \\
\hline SW & 9 & $1.23 \pm 0.1$ & & & \\
SS & 9 & & $2.27 \pm 0.4$ & & \\
FS & 9 & & $2.60 \pm 0.2$ & & \\
PC & 9 & & & $4.48 \pm 0.2$ & $10.26 \pm 1.8$ \\
MVSN & 9 & & & & 1.26 \\
\hline
\end{tabular}

Means for groups in homogeneous subsets are displayed. *a,b,c,d are significantly different groups MVSN: Mean values of spore numbers at the beginning of the field study.

Mean values of spore numbers based on the application methods (SW, SS, FS, PC) got from the last day $\left(21^{\text {th }}\right)$ of field study.

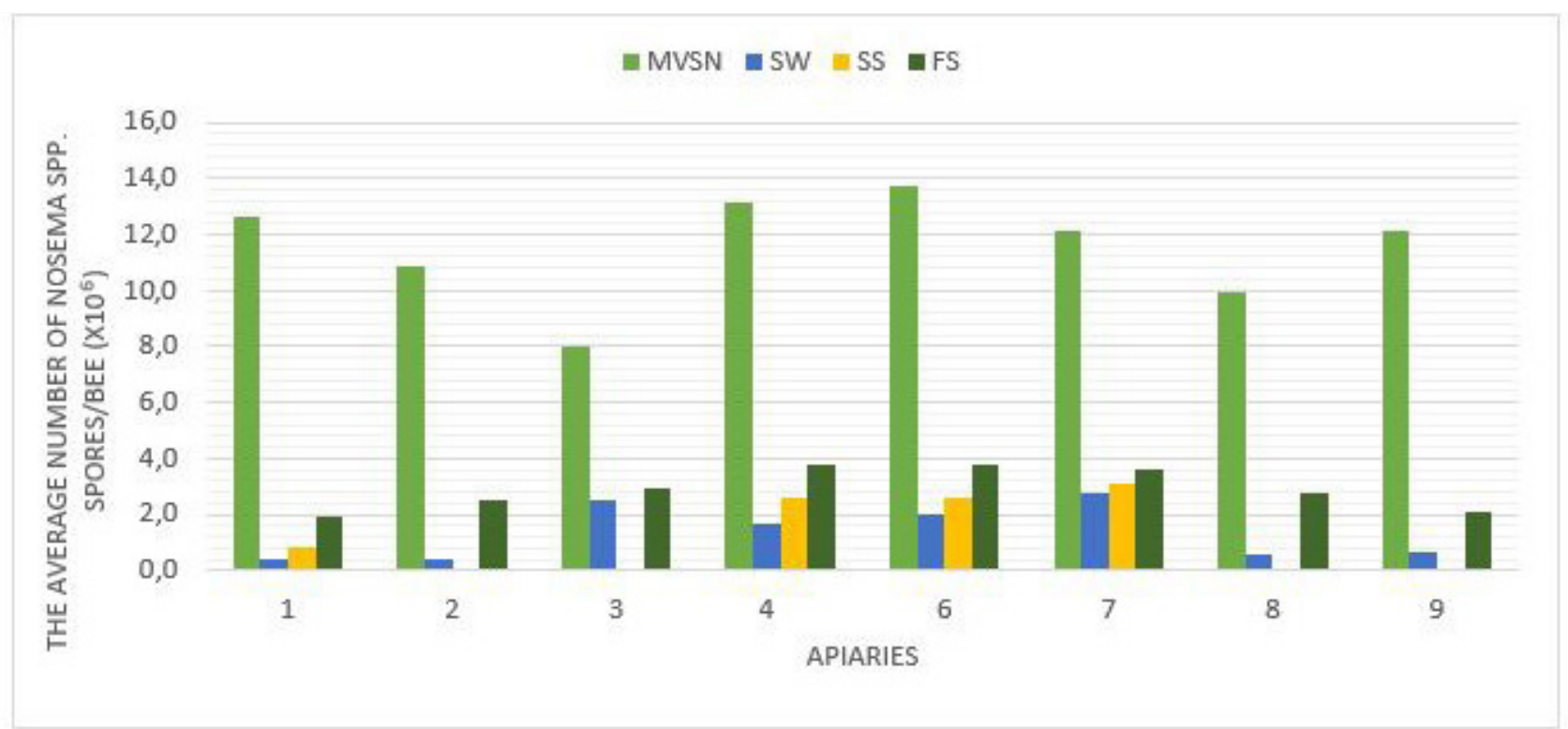

Fig. 5. Comparative results of the average number of Nosema spp. spores in the apiaries differentiated by application method. *MVSN: Mean values of spore numbers at the beginning of the field study. SW:Mean values of the final spore numbers after the application of spraying with water at the end of the field study SS:Mean values of the final spore numbers after the application of spraying with syrup at the end of the field study FS:Mean values of the final spore numbers after the application of feeding with syrup at the end of the field study **Missing data belong to SS in 2,3,8,9 th apiaries could not be shown because of robbing behaviour. All of the experiments' data on individual basis are presented in supplementary table online.

was more effective than a single dose (250 $\mu \mathrm{L})$. When groups receiving one dose were compared with those two doses of HEOEM, a significant decrease in the number of Nosema spores was found in cages receiving two doses (ANOVA,
$F=12.453, d f=7, \operatorname{Sig}=0.000, P<0.001, N=20)$.

Differences between groups determined by one-way ANOVA test were classified with Duncan's test (SPSS v. 22), which provided two results from the experiments, one of which was 
that HEOEM $(500 \mu \mathrm{L})$ was more effective than the fumagillin $(20 \mu \mathrm{g} / \mathrm{mL})$ applied to the positive control (Duncan's group $a^{\star}, b^{\star}$, and $c^{\star}$ ). The values of all efficacy results are summarized in Tab. 3.

\section{The efficacy of HEOEM based on results of field study}

In the field study experiments, no colony death occurred in any of the experimental groups. As in the cage experiments, this demonstrates that HEOEM has no toxic effect on honey bees.

A significant decrease in the number of Nosema spp. spores before and after the application of HEOEM was confirmed through one-way ANOVA $(F=19.925, d f=11, \quad S i g=000, P<0.001$, $\mathrm{N}=72$ ).

HEOEM was found to be effective, causing an approximately $92-95 \%$ drop in spore numbers. The decrease in ratio of spore numbers for fumagillin was found to be $60-65 \%$ in the positive controls. The increase in spore numbers in the negative control colonies was found to be four-fold from the beginning to the end of the three weeks. In addition to the effects of HEOEM, another aim of the field study was to determine the most beneficial application method. The differences between application methods were classified with Duncan's test analysis (SPSS v. 22) (Tab. 4). Spraying with water (SW) was found to be the most effective application method to lower the number of Nosema spores. The greatest decrease in spore number was recorded following syrup-spray application (SS). Nevertheless, eight colonies developed robbing behaviour, so the experiment could not be continued in these colonies. In addition, beekeepers gave negative feedback concerning the use of this application method. Nosema spp. spore numbers also declined after the feeding syrup application (FS), which was most preferred by the beekeepers. During the experiments, the beekeepers described this method as the easiest and most familiar method for Nosema spp. treatment. All results from the field study were diagrammed in Fig. 5.

\section{DISCUSSION}

This study revealed that the HEOEM effectively reduces the number of Nosema spp. spores and validated the mixture of herbal essential oil extracts. Some components of the HEOEM have been studied as single agents against nosemosis and other bee diseases, but the herbal extracts studied to date have not shown efficacious performance individually compared to a combination of them (Costa et al., 2010; Botias et al., 2013; Radoi et al., 2014; Damiani et al., 2014). It is clear that the success found in this study is also due to the synergistic effect among the herbal extracts in the HEOEM. The mechanism of this synergy may be examined chemically in further studies.

The plants comprising the HEOEM mixture are easily accessible and cultivated (Borugă et al., 2014; Bajer et al., 2016; Caputo et al., 2017; Chanbari et al., 2017; Khedher et al., 2017; Andrade et al., 2018). This is the main advantage of producing the HEOEM. Because the plants are members of the Mediterranean and Aegean lines (the subtropical regions), they contain more components in their essential oil extracts (Sorkun, 2008; Andrade et al., 2018). The rich content of their extracts facilitates the synergistic effects among them, so it was expected that the HEOEM would have a marked effect against Nosema spp. However, content richness may not always offer a positive benefit. The combination of these plants with major active components and a wide range of bioactivity could have had a toxic effect on bees. The absence of such an effect in both cage experiments and field studies was one of the most valuable results of the study. The studies reflected that the use of these plant materials, which are of natural origin, reduced the stress factors on honey bees (Evans \& Schwarz, 2011; Damiani et al., 2014). Regarding the parameters for measuring HEOEM efficacy, the mixture also performed well in terms of not harming bees or affecting colony development.

Such antimicrobial agents as fumagillin, which was used as a positive control in this study, leave residues in the honey and honey combs, a 
drawback that has been known for years (Lopez et al., 2008). Furthermore, the rate of reduction in spore numbers was lower than that of the HEOEM. Previous studies have shown that some herbal extracts do not leave residues, further supporting the favourable comparison of the HEOEM to fumagillin (Costa et al., 2010; Porrini et al., 2011; Botias et al., 2013; Bravo et al., 2017). Aside from residues, the main problem is the resistance of Nosema spp. to fumagillin. These results all confirm that the HEOEM could be a good alternative to fumagillin in the near future from the standpoint of many parameters. Regarding application methods, spraying with water (SW) was seen as the most effective way to use the HEOEM. The method enables the HEOEM to reach the entire colony through both feeding and direct contact. Considering the ways Nosema spp. spores are transmitted in bee colonies (Paxton et al., 2007; Zanet et al., 2019), contact with HEOEM even on beekeeping materials, comb foundations and frames will be a very effective way to reduce infection levels and contamination risks. This method prevents the spread of spores in the colony thereby accelerates the treatment.

Additionally, the spray method induced grooming behaviour in the bees during the experiments. Grooming behaviour is known to promote a hygienic colony (Spivak, 1996) but can also accelerate the spread of Nosema spp. spores (Natsopoulou et al., 2016; Zanet et al., 2019). On the other hand, spray-induced grooming behaviour provided an almost equal consumption of HEOEM by all bees in the colony. Thus, the negative effect of grooming behaviour on the spread of Nosema spp. spores disappeared due to the homogenous spread of HEOEM in the hive. In nature, grooming behaviour is developed by bees to ensure hygiene in colonies (Spivak, 1996). In this study, the use of HEOEM also improved grooming behavior. All these effects observed in SW can be attributed to the homogenous distribution of HEOEM throughout the colonies.

Spraying with syrup (SS) as the application method was tested for the first time in this study. This method was preferred because that
HEOEM consumption was assumed to increase in the colony because of the syrup. Furthermore, the syrup contains sugar that can induce grooming behaviour (Stevanovic et al., 2012). SS may have additional advantages compared to spraying with water (SW) due to the possibility of higher consumption, but it induced robbing behaviour, so this method failed in apiaries 2, 3, 8 and 9. A lack of sources, poor nutrients, and starving are thought to have caused the robbing behaviour with respect to the season (April 2019). Robbing behaviour is known to contribute to the spread of Nosema spp. spores in colonies (Evans \& Schwarz, 2011), and therefore this method is not applicable for beekeepers unless robbing behaviour can be prevented. Beekeepers preferred feeding with syrup (FS) due to the ease of use (Higes et al., 2014), but certain problems related to consumption were encountered, as with SS. The honey bees need to reach the syrup box and return to the frame. A lack of energy in honey bees as the main symptom of nosemosis (Higes et al., 2006, 2008; Fries et al., 2013) led to two problems; the honey bees could not consume enough HEOEM and died in the sugar syrup, and the HEOEM did not reach the honey bees in the hive, because syrup consumption was not uniform among the bees causing a slower reduction of Nosema spp. spores. However, long-term use of HEOEM by FS may effectively reduce Nosema spp. spores.

There have been many studies on the antimicrobial, antifungal, antioxidant and other properties of the plants in HEOEM (Borugă et al., 2014; Bajer et al., 2016; Caputo et al., 2017; Ghanbari et al., 2017; Khedher et al., 2017; Andrade et al., 2018). They have reported the doses of essential oils used in their experiments (e.g., Rosmarinus officinalis, $6.4 \mu \mathrm{g} / \mu \mathrm{L} ;$ Thymus vulgaris, 16.3 $\mu \mathrm{g} / \mu \mathrm{L}$; and Plantago lanceolata, $25.2 \mu \mathrm{g} / \mu \mathrm{L})$, and served as a reference for determining the doses in this study. However, both the concentration of the HEOEM solution and the application dose were observed to be effective even in smaller amounts than expected. This result proves that HEOEM is more effective as a mixture. Although there was no statistically significant difference, the decrease in the number of Nosema spp. 
spores on the $9^{\text {th }}$ and $12^{\text {th }}$ days of the experiments drew our attention. For this reason, the usage period of HEOEM is recommended to be be at least fifteen days in order to include the $9^{\text {th }}$ and $12^{\text {th }}$ days in the three-day intervals.

A number of parameters that can be observed and measured numerically were used to verify the effectiveness of HEOEM. The development of colonies, the presence of young individuals, and the disappearance of clinical symptoms were observable. A significant decrease in the number of Nosema spp. spores was the numerically measurable parameter that was further analysed statistically. The sum of all parameters confirmed the treatment efficacy of HEOEM.

In this study, the effect of HEOEM against nosemosis was tested through several application methods. The results showed that a mix of herbal extracts was more effective than fumagillin used legally until recently and/or single herbal extract in agreement with other studies. HEOEM is effective in reducing any type of Nosema spp. spores, regardless of application method. In a comparison application methods, SW was shown to be the most effective for treating Nosema spp. with HEOEM.

In a more detailed view of results from both cage experiments and field studies and the advantages of the extraction process, its effective dose is determined to be $500 \mu \mathrm{L}$ in cages and 2,000 $\mu \mathrm{L}$ per frame in hives. Since more significant decreases in Nosema spore numbers were observed after the $9^{\text {th }}$ and $12^{\text {th }}$ days, the duration of application is suggested to be at least fifteen days at intervals of three days. With these features and the non-toxic effects of its herbal ingredients, HEOEM can be considered an alternative treatment agent against Nosema infections.

\section{ACKNOWLEDGEMENT}

This study was financially supported by F.Bi. P98 project number of Hacettepe University Revolving Fund Management Office. We would like to thank to Asatim (ArıTürk) Company for the support of this HEOEM R\&D study for producing process of Nosemit ${ }^{\circledR}$.

\section{REFERENCES}

Andrade, J. M., Faustino, C., Garcia, C., Ladeiras, D., Reis, C. P., Rijo, P. (2018). Rosmarinus officinalis L.: an update review of its phytochemistry and biological activity. Future Science, OA.4(4),FSO283. http://doi. org/10.4155/fsoa-2017-0124

Azmir J., Zaidul Mahmudur S.M., Rahmman, M.M., Sharif, K.M., Mohamed, A., Sahena, F., ... Omar, A.K.M. (2013). Techniques for extraction of bioactive compounds from plant materials: A review. Journal of Food Engineering, 177,426-436.

Bajer, T., Janda, V., Bajerová, P., Kremr, D., Eisner, A.,Ventura, K. (2016). Chemical composition of essential oils from Plantago lanceolata L. leaves extracted by hydrodistillation. International Journal of Food Science, 53(3), 1576-1584. http://doi. org/10.1007/s13197-015-2083-x

Borugă, O., Jianu, C., Mişcă, C., Goleţ, I., Gruia, A., T, Horhat, F. G. (2014). Thymus vulgaris essential oil: chemical composition and antimicrobial activity. Journal of Medicine and Life, 7 (Spec. iss. 3), 56-60

Botías, C., Martín-Hernández, R., Meana, A., Higes, M. (2013). Screening alternative therapies to control Nosemosis type $C$ in honey bee (Apis mellifera iberiensis) colonies. Research Veterinary Science, 95(3), 1041-1045. http://doi.org/10.1016/j. rvsc.2013.09.012

Bravo, J., Carbonell, V., Sepúlveda, B., Delporte, C., Valdovinos, C.E., Martín-Hernández, R., Higes, M. (2017). Antifungal activity of the essential oil obtained from Cryptocarya alba against infection in honey bees by Nosema ceranae. Journal of Invertebrate Pathology, 49, 141-147. http://doi. org/10.1016/j.jip.2017.08.012

Caputo, L., Nazzaro, F., Souza, L.F. (2017). Laurus nobilis. Composition of Essential Oil and Its Biological Activities. Molecules, 22(6), 930. http:// doi.org/10.3390/molecules22060930

Celik, N., \& Akpulat, H.A. (2008). Achillea sivasica 
(Asteraceae: sect. Babounya (DC.) O. Hoffm.), a new species from inner Anatolia, Turkey. Kew Bulletin, 63(3), 485-489. http://doi.org/10.1007/s12225008-9055-5

Chen, Y., Evans, J.D., Zhou, L.,Boncristiani, H., Kimura, K., Xiao, T., Litkowski, A.M., Pettis, J.S. (2009). Asymmetrical coexistence of Nosema ceranae and Nosema apis in honey bees. Journal of Invertebrate Pathology, 101, 205-209. http://doi.org/10.1016/j. jip.2009.05.012

Chen, Y.P., Evans, J.D., Smith, J.B., Pettis, J.S. (2008). Nosema ceranae is a long-present and widespread microsporidian infection of the European honeybee (Apis mellifera) in the United States. Journal of Invertebrate Pathology, 97, 186-188. http://doi. org/10.1016/j.jip.2007.07.010

Costa, C., Lodesani, M., Maistrello, L. (2010). Effect of thymol and resveratrol administered with candy or syrup on the development of Nosema ceranae and on the longevity of honeybees (Apis mellifera $L$.) in laboratory conditions. Apidologie, 47(2), 141-150. http://doi.org/10.1051/apido/2009070

Damiani, N., Fernández, N.J., Porrini, M.P., Gende, L.B., Álvarez, E., Buffa, F., ... Eguaras, M.J. (2014). Laurel leaf extracts for honeybee pest and disease management: antimicrobial, microsporicidal, and acaricidal activity. Parasitology Research, 173(2), 701-709. http://doi.org/10.1007/s00436-0133698-3

Evans, J.D., \& Schwarz, R.S. (2011). Bees brought to their knees: microbes affecting honey bee health. Trends Microbiology, 19(12), 614-620. http:// doi.org/10.1016/j.tim.2011.09.003

Fries, I., Chauzat, M.P., Chen, Y.P., Doublet, V., Genersch, E., Gisder, S., ... Paxton, R.J. (2013). Standard methods for Nosemaresearch. Journal of Apicultural Research, 52(1), 1-28. http://doi.org/10.3896/IBRA.1.52.1.14

Ghanbari, M., Souri, M. K, Omidbaigi, R. (2017). Chemical Composition of the Essential Oil of Achillea millefoliumL. from north-west of Iran. Zeitschrift fur Arznei- \& Gewurzpflanzen, 22(2), 69-71. http://doi. org/10.25135/ґnp.11.17.03.024

Higes, M., Gómez-Moracho, T., Rodriguez-García, C. Botias, C., Martín-Hernández, R. (2014). Preliminary effect of an experimental treatment with "Nozevit"," (a phyto-pharmacological preparation) for Nosema ceranae control. Journal of Apicultural Research, 53(4), 472-474. http://doi.org/10.3896/ IBRA.1.53.4.03

Higes, M., Martín, R., Meana, A. (2006). Nosema ceranae, a new microsporidian parasite in honeybees in Europe. Journal of Invertebrate Pathology, 9z(2), 95-93. http://doi.org/10.1016/j.jip.2006.02.005

Higes, M., Martín-Hernández, R., Botías, C., Bailón, E.G., González-Porto, A.V., Barrios, L., ..., Meana, A. (2008). How natural infection by Nosema ceranae causes honeybee colony collapse. Environmental Microbiology, 1010), 2659-2669. http://doi. org/10.1111/j.1462-2920.2008.01687.x

Honda, G., Yesilada, E., Tabata, M., Sezik, E., Fujita, T., Takeda, Y., Takaishi, Y., Tanaka, T. (1996). Traditional medicine in Turkey VI. Folk medicine in West Anatolia: Afyon, Kutahya, Denizli, Mugla, Aydin provinces. Journal of Ethnopharmacology, 53, 75-87. http://doi. org/10.1016/S0378-8741(96)01426-2

https://www.henriettes-herb.com/eclectic/kings/ rumex-acet.html

Isbilir, S.S., \& Sagiroglu, A. (2013). Total phenolic content, antiradical and antioxidant activities of wild and cultivated Rumex acetosella L. extracts. Biological Agriculture and Horticulture, 294), 219-226. http://doi.org/10.1080/01448765.2 013.827992

Khedher, M., Khedher, S. B, Chaieb, I., Tounsi, S., Hammami, M. (2017). Chemical composition and biological activities of Salvia officinalis essential oil from Tunisia. EXCLIJournal. 16, 160-173. http://doi. org/10.17179/excli2016-832.

Lopez, M.I., Pettis, J.S., Smith, I.B., Chu, P.S. (2008). Multiclass determination and confirmation of antibiotic residues in honey using LC-MS/MS. Journal of Agricultural Food Chemistry, 56(5), 1553-1559. 


\section{J. APRC. SCLI. VOL. 65 NO. 1 2021}

http://doi.org/10.1021/jf073236w

Martín-Hernández, R،, Botías, C., Bailón, E.G., MartínezSalvador, A., Prieto, L., Meana, A., Higes, M. (2012). Microsporidia infecting Apis mellifera. coexistence or competition. Is Nosema ceranae replacing Nosema apis? EnvironmentalMicrobiology, 14(8), 2127-2138. http://doi.org/10.1111/j.1462-2920.2011.02645.x

Natsopoulou, M.E., McMahon, D.P., Paxton, R.J. (2016). Parasites modulate within-colony activity and accelerate the temporal polyethism schedule of a social insect, the honey bee. Behavioral Ecology and Sociobiology, 707), 1019-1031. http://doi. org/10.1007/s00265-015-2019-5

Naug, D., \& Gibbs, A. (2009). Behavioral changes mediated by hunger in honeybees infected with Nosema ceranae. Apidologie, 40(6), 595-599. http:// doi.org/10.1051/apido/2009039

Neumann, P." \& Carreck, N.L. (2010). Honey bee colony losses. Journal of Apicultural Research, 49(1), 1-6. http://doi.org/10.3896//BRA.1.49.1.01

Ouzzara, M.L., Louaera, W., Zemanea, A., Meniaia, A.H. (2015). Comparison of the Performances of Hydrodistillation and Supercritical $\mathrm{CO}_{2}$ Extraction Processes for Essential Oil Extraction from Rosemary (Rosmarinus officinalis L.). Chemical Engineering Transactions 43, 1129-1134. http://doi. org/10.3303/CET1543189

Özcan, M., \& Chalchat, J.C. (2004). Aroma profile of Thymus vulgarisL. growing wild in Turkey. Bulgarian Journal of Plant Physiology, 303-4), 68-73.

Özkırım, A., Schiesser, A., Keskin, N. (2019). Dynamics of Nosema apis and Nosema ceranae Co-Infection Seasonally in Honey Bee (Apis mellifera L.) Colonies. Journal of Apicultural Science, 63(1), 41-48. http:// doi.org/10.2478/jas-2019-0001

Özkırım, A., Keskin, N., Kürkçüoğlu, M., Başer, K.H.C. (2012). Evaluation of some essential oils as alternative antibiotics against American foulbrood agent Paenibacillus larvae on honey bees Apis mellifera L. Journal of Essential Oil Research, 24(5),
465-470. http://doi.org/10.1080/10412905.2012.7 03504

Paxton, R.J., Klee, J., Korpela S., Fries, I. (2007). Nosema ceranae has infected Apis mellifera in Europe since at least 1998 and may be more virulent than Nosema apis. Apidologie, 38(6), 565-558. http://doi. org/10.1051/apido:2007037

Porrini, M.P., Fernández, N.J., Garrido, P.M., Gende, L.B., Medici, S.K., Eguaras, M.J. (2011). In vivo evaluation of antiparasitic activity of plant extracts on Nosema ceranae (Microsporidia). Apidologie, 4ح(6), 700-707. http://doi.org/10.1007/s13592-011-0076-y

Radoi, I., Sapcaliu, A., Mateescu, C., Pop, A., Savu, V. (2014). In vitro screening of hydroalcoholic plant extracts to control Nosema apis infection. Journal of Biotechnology, 185, 46. http://doi.org/10.1016/j. jbiotec.2014.07.154

Sorkun, K., (2008). Turkey's nectarine plants, pollen and honeys. 1. Press/341. Palm Publication.

Spivak, M. (1996). Honey bee hygienic behavior and defenseagainst Varroajacobsoni. Apidologie, 274), 245-260. http://doi.org/10.1051/apido:19960407

Stevanovic, J., Stanimirovic, Z., Lakic, N., Djelic, N., Radovic, I. (2012). Stimulating effect of sugar dusting on honey bee grooming behaviour. Entomologia Experimentalis et Applicata, 143(1), 23-30. http:// doi.org/10.1111/j.1570-7458.2012.01231.x

Walker, J.B., Sytsma, K.J., Treutlein, J., Wink, M. (2004). Salvia (Lamiaceae) is not monophyletic: implications for the systematics, radiation, and ecological specializations of Salvia and tribe Mentheae. American Journal of Botany, 91, 1115-1125. http:// doi.org/10.3732/ajb.91.7.1115

Zanet, S., Battisti, E., Alciati, R., Trisciuoglio, A., Cauda, C., Ferroglio, E. (2019). Nosema ceranae contamination in bee keeping material: the use of ozone as disinfection method. Journal of Apicultural Research, 58(7), 62-66. http://doi.org/10.1080/0021 8839.2018.1517989 